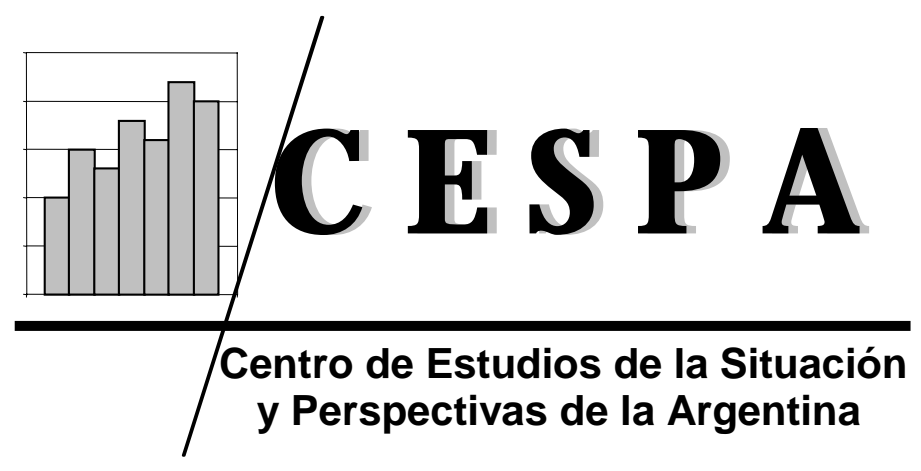

\title{
LAS CUENTAS PÚBLICAS Y LA CRISIS DE LA CONVERTIBILIDAD EN ARGENTINA
}

\author{
Mario Damill* \\ Roberto Frenkel \\ Luciana Juvenal \\ Agosto 2003
}

Documento de Trabajo no 4 (DT4)

Universidad de Buenos Aires

Facultad de Ciencias Económicas Instituto de Investigaciones económicas 


\section{Introducción}

En este trabajo se abordan dos tópicos centrales en las controversias acerca del régimen de convertibilidad establecido en la Argentina en 1991 y de su crisis, que alcanzó su desenlace a fines de 2001.

El primero de ellos se refiere a las principales características de ese esquema de políticas y al desempeño macroeconómico al que dio lugar: ¿puede considerarse que el régimen de convertibilidad y su crisis constituyen un caso especial, o bien esas experiencias comparten los rasgos estilizados de otras vividas en diferentes economías a lo largo del proceso de globalización financiera? Sostenemos aquí que la experiencia argentina de los años noventa se asemeja a otros casos de liberalización comercial y financiera de América Latina que desembocaron en episodios de crisis. Argumentamos que en esas diversas experiencias puede observarse un mismo conjunto de factores críticos, y que los desempeños macroeconómicos y las crisis encuentran, en esos distintos casos, una explicación común.

El segundo punto se refiere a la cuestión fiscal. La explicación predominante de la crisis argentina se apoya en una dinámica insostenible de la deuda pública, determinada por la política fiscal seguida en la segunda mitad de la década de los noventa. En nuestra visión, la dinámica de la deuda pública se debió centralmente al efecto acumulativo de la suba de las tasas de interés (impulsadas por el aumento de la prima de riesgo país), a partir de las crisis del sudeste de Asia y de Rusia. Los pagos de intereses fueron el principal factor por detrás del incremento del déficit fiscal en el período 1998-2001. El sistema de jubilaciones y pensiones también contribuyó a ese aumento. La caída de los ingresos del sistema previsional público fue principalmente el resultado de la recesión y de la contracción del empleo que se produjo desde mediados de 1998. Así, se trató también, en buena medida, de un efecto indirecto de las nuevas condiciones financieras. El déficit fiscal se incrementó a pesar de un significativo aumento del resultado primario de las cuentas públicas. A fin de fundamentar sólidamente estos argumentos, revisamos aquí los datos fiscales incorporando nuevas estimaciones de la deuda pública y trazamos un nuevo cuadro cuantitativo de la evolución de las cuentas fiscales en los años noventa.

En la próxima sección abordamos la primera de las cuestiones planteadas, es decir, la relativa a la explicación común de diversos episodios de crisis. Luego, en la sección 3, enfocamos la cuestión fiscal en la Argentina de los

Centro de Estudios de Estado y Sociedad -CEDES-, Buenos Aires, en colaboración con el CESPA. 
noventa. Cierra el trabajo una sección con reflexiones finales acerca del papel de las cuentas fiscales y la deuda pública en la crisis.

\section{Las crisis externas ${ }^{1}$}

\subsection{Las crisis de la etapa reciente}

En la nueva etapa de la evolución financiera internacional que se inicia en los años noventa varios países latinoamericanos han experimentado crisis externas y financieras con dramáticos efectos reales. Las crisis involucran generalmente altos costos económicos y sociales y retrocesos en el crecimiento. El contagio regional es otro efecto destacable. La crisis en un país repercute negativamente sobre el precio del financiamiento y los flujos de capital de otros países. Este fenómeno tuvo su primera manifestación ostensible en el período con la crisis mexicana de 1994-95. El "efecto tequila" impactó en la región y en otros mercados emergentes y fue detonador de la crisis argentina de 1995. Los efectos de contagio se hicieron más amplios a partir de 1997. La crisis asiática de 1997-98 y la de la economía rusa en 1998 tuvieron repercusiones universales y el contagio no sólo afectó a Brasil y Argentina, sino también a países latinoamericanos en situaciones relativamente más robustas [Ffrench-Davis (2001)].

Las crisis de México (1994-95), Argentina (1995), Brasil (1998-99) y nuevamente Argentina (2001-02), estallaron en los países que habían recibido los mayores flujos de capital en las fases de auge previas. Estos países son, a su vez, las economías de mayor tamaño de América Latina y los mayores "mercados emergentes" constituidos en la región.

Basta un examen somero de los casos mencionados para destacar ciertos rasgos comunes de los contextos institucionales y de política económica en que se presentaron las crisis: 1) el tipo de cambio nominal era fijo o cuasi-fijo; 2) el tipo de cambio real estaba apreciado; 3) no existían prácticamente barreras al libre movimiento de capitales; 4) los ingresos de capitales del período de auge previo fueron de gran magnitud en comparación con el tamaño de los mercados nacionales de dinero y capitales preexistentes; 5) la regulación de los sistemas financieros nacionales en la etapa de auge fue débil y permisiva ${ }^{2}$.

\footnotetext{
1

Esta sección se basa en Frenkel (2003).

2 La regulación del sistema financiero se reformó y fortaleció en Argentina después de la crisis de 1995. De modo que fue más robusta en la fase de auge de ingresos de capitales de 1996-97. Sin embargo, en Argentina existía un riesgo cambiario sistémico por la dolarización parcial del sistema financiero interno. Mientras los bancos tenían calzados sus activos y pasivos locales en dólares y no aparentaban enfrentar riesgo cambiario
} 
Análisis más pormenorizados de las experiencias mencionadas muestran en todas ellas, además de las características ya referidas, una dinámica macroeconómica de ciclo, con una fase inicial expansiva, seguida de un período de estancamiento o recesión, una creciente fragilidad financiera y externa y, finalmente, la crisis financiera y cambiaria. La economía argentina experimentó el ciclo dos veces en la década, porque el régimen de convertibilidad sobrevivió a la crisis del efecto Tequila en 1995. Después de 1995 la economía argentina experimentó otra breve fase expansiva respaldada por un nuevo incremento en el ingreso de capitales que se extendió hasta la crisis asiática. El punto de inflexión de este segundo ciclo se alcanzó en 1998 . $^{3}$ Los contextos institucionales y de política macroeconómica cuyas características enumeramos arriba se configuraron por la aplicación de programas que combinaron reformas tales como la apertura comercial y la apertura y liberalización de la cuenta de capital - junto con privatizaciones, reformas fiscales y medidas desregulatorias en otros mercados - con políticas macroeconómicas antiinflacionarias en las que el tipo de cambio fijo o cuasifijo jugaba un papel crucial. México puso en práctica un programa de este tipo en 1988, Argentina en 1991 y Brasil en 1994.

\subsection{Los experimentos del Cono Sur}

Algunas de las tempranas experiencias regionales de inserción financiera internacional de los años setenta - las de Argentina y Chile - anticiparon los modelos que se generalizarían en los años noventa. Los llamados "experimentos de liberalización del Cono Sur" combinaron drásticas reformas financieras y comerciales con esquemas macroeconómicos de tipo de cambio prefijado y política monetaria pasiva. Las reformas involucraron la apertura y desregulación de los flujos de capital, la liberalización del mercado financiero local y la apertura comercial. La prefijación del tipo de cambio (las tablitas) estaba orientada a la reducción de la inflación. Estas experiencias de política resultaron en procesos de apertura y desregulación financiera y comercial que se desarrollaron en contextos de oferta abundante de fondos externos y condiciones de tipo de cambio fijo y apreciado [Fanelli y Frenkel (1993) y Frenkel (2002)].

En esas experiencias de los años setenta se encuentra la misma conjunción de condiciones locales y auge de los flujos de capital que se observa en los casos

individualmente, buena parte del crédito en dólares era adeudado por agentes con ingresos en pesos provenientes de actividades no comerciables.

No presentaremos aquí un análisis detallado de la experiencia argentina de los noventa. El mismo puede encontrarse en Damill, Frenkel y Maurizio (2002 y 2003), y en Damill y Frenkel (2003). 
críticos de los noventa. Además, los procesos a que dieron lugar los experimentos del Cono Sur son similares a los desarrollos que posteriormente condujeron a las crisis de México, Brasil y Argentina en la etapa reciente. Aunque la duración de las experiencias de los setenta fue menor que la de los casos recientes, la dinámica macroeconómica muestra el mismo ciclo de auge, retracción y crisis.

Chile primero, y poco después Argentina iniciaron sus nuevos programas cambiarios en 1978. Hacia fines de 1979, cuando la política monetaria de Estados Unidos elevó la tasa de interés, Argentina y Chile ya mostraban grandes deudas externas e importantes déficit de cuenta corriente. De ese momento en adelante las incrementadas tasas internacionales de interés contribuyeron adicionalmente a la fragilidad externa. Las crisis estallaron poco tiempo después. El régimen cambiario colapsó en Argentina a principios de 1981 y en Chile en 1982. Los mercados financieros externos se cerraron para ambas economías en 1982 y en ambos casos fueron instrumentados rescates masivos de los sistemas financieros locales con alto costo fiscal. Ambas economías entraron en profundas recesiones. El aumento de la tasa de interés internacional a fines de 1979 jugó un papel acelerador. Sin embargo, las experiencias muestran evidencia de un ciclo endógeno, con un punto de inflexión y una posterior fase de contracción que emergen independientemente del de la evolución de la tasa de interés internacional. Este ciclo, como en los casos más recientes, involucra el sistema financiero interno, la evolución de las cuentas externas y las reservas de divisas y el crecimiento de la deuda.

Hay varias razones que justifican traer a la discusión las experiencias del Cono Sur. Ni el déficit fiscal ni la existencia de garantías públicas sobre los depósitos bancarios - elemento potencialmente generador de "moral hazard"jugaron papeles significativos en esas crisis. Ambos rasgos estaban presentes en Argentina, pero Chile tenía superávit fiscal y la garantía de los depósitos había sido eliminada con el explícito propósito de hacer más eficiente y menos riesgoso el sistema financiero.

El FMI dio fuerte apoyo a esas experiencias de política. En 1980 y 1981, cuando las cuentas externas de Chile exhibían grandes déficit de cuenta corriente, el FMI sostuvo que esa situación no debía ser motivo de preocupación mientras no tuviera el déficit fiscal como contraparte - como no lo tenía en Chile entonces ${ }^{4}$. El mismo diagnóstico sostuvo más adelante el FMI con relación a la situación de México en $1994^{5}$. En ambas oportunidades el fundamento del diagnóstico se apoyó en el argumento según el cuál la

\footnotetext{
${ }_{5}^{4}$ Véase, por ejemplo, Robichek (1981), citado en Díaz Alejandro (1985).

5 Michel Camdessus sostuvo una posición semejante con relación a México, en una visita a ese país en 1994.
} 
conducta racional del sector privado garantizaba la asignación eficiente de los recursos tomados en préstamo del exterior y garantizaba su repago.

La crisis de los experimentos de Cono Sur causó un impacto intelectual importante. El caso de Chile fue particularmente impactante porque contaba con todos los ingredientes que debían garantizar su éxito y estabilidad, de acuerdo con la teoría en boga que fundamentaba las políticas. Los experimentos estaban fundados en una versión del moderno "enfoque monetario del balance de pagos", la visión nacida en la Universidad de Chicago al calor del reciente restablecimiento de un mercado mundial de capitales.

Los trabajos y debates alrededor de las experiencias del Cono Sur dieron lugar a un cuerpo de literatura económica: la llamada "sequencing literature" [Fanelli y Frenkel (1993)]. La conclusión principal de esta literatura es que las crisis resultaron de una inadecuada secuencia de las reformas. Básicamente, que las crisis fueron causadas por la prematura adopción de la apertura financiera. Su consecuente recomendación de política es que los mercados de capitales deben abrirse solamente después que la economía se encuentre estabilizada, abierta al comercio internacional y con un sistema financiero robusto. Esto es, al final de la aplicación de una secuencia de políticas - las que más tarde configurarían el núcleo del Consenso de Washington - y solamente después que las primeras reformas muestren plenamente sus efectos esperados.

Estas observaciones ponen en evidencia que en la primera mitad de la década de los noventa, cuando se experimentaba un nuevo auge de los flujos de capital, no faltaba experiencia histórica, ni trabajo analítico, ni recomendaciones de política que sirvieran de antecedentes para examinar los procesos que se estaban desarrollando entonces en México y Argentina. Los experimentos del Cono Sur habían tenido lugar apenas una década atrás y habían sido profusamente analizados. Sin embargo, la memoria de estos casos y las lecciones extraídas de ellos no apareció en el FMI, ni en el trabajo de los analistas de los mercados, ni en gran parte de la producción académica. Es aún más llamativo que olvidaran las experiencias del Cono Sur y la "sequencing literature" algunos de quienes participaron activamente en ese debate y contribuyeron a la literatura, para más tarde ocupar posiciones relevantes en la nueva etapa (por ejemplo, la Sra. Anne Krueger -actual Director Gerente del FMI- [Krueger (1984)] y el Sr. Sebastián Edwards -ex Economista Jefe para América Latina del Banco Mundial- [Edwards (1986)] $)^{6}$. Tal fue la pérdida

\footnotetext{
6

6 Llamamos la atención sobre el "olvido" de la literatura mainstream acerca de "sequencing". Quizá menos llamativa (porque es un hecho más frecuente) es la total ignorancia de la literatura producida en los países y
} 
de memoria de las crisis que en la interpretación convencional que se asentó después de la crisis de México, ésta habría sido tan sorprendente como un relámpago en un día soleado.

\subsection{La dinámica cíclica que conduce a la crisis ${ }^{7}$}

El punto de partida del ciclo que caracteriza los casos de los años setenta y noventa es la conjunción de los programas locales con un momento de auge de los flujos de capital hacia los mercados emergentes. Es precisamente la abundancia de financiamiento internacional a bajo precio lo que hace viable ex - ante los paquetes de políticas.

El lanzamiento de los programas es seguido de masivos ingresos de capital y una primera fase de acumulación de reservas y elevadas tasas de crecimiento de la moneda y el crédito. Hay una fuerte expansión de la demanda interna y burbujas de aumentos de precios de activos reales y financieros, tales como tierra, inmuebles y acciones. Los efectos sobre los precios de los activos y los efectos sobre las cantidades de moneda y crédito son muy importantes porque los ingresos de capitales son grandes en relación con el tamaño de los mercados locales. Los sistemas financieros y los mercados de capital internos son relativamente pequeños y poco diversificados. Hay un menú de activos pobre y un grado de bancarización reducido. El sistema financiero local administraba antes pocos recursos y no está preparado para asignar eficientemente una masa de crédito que se multiplica. Por la misma razón, es reducida la capacidad de supervisión de las autoridades en un sistema que se expande rápidamente, tanto en volumen como en número de intermediarios. Con un tipo de cambio nominal fijo o cuasi-fijo que goza inicialmente de gran credibilidad, la inversión en activos locales tiene alta rentabilidad en dólares. Hay fuertes incentivos a la adopción de posiciones en activos locales financiadas con endeudamiento en moneda internacional.

El tipo de cambio real estaba inicialmente apreciado o tiende a apreciarse en la fase expansiva porque la inflación resulta mayor que la suma de las tasas de devaluación prefijadas (cero en los casos de tipo de cambio fijo) más la inflación internacional. La presión de la rápida expansión de la demanda sobre los sectores no comerciables contribuye a la apreciación.

\footnotetext{
por analistas menos convencionales (véase para Argentina: Frenkel (1980, 1983a y 1983b) y Damill y Frenkel (1987); para Chile: Arellano (1983), Ffrench-Davis y Arellano (1983) y Díaz Alejandro (1985)).

7 La narrativa que planteamos aquí se funda en un modelo inspirado en las experiencias de Argentina y Chile que se encuentra en Frenkel (1983a). El modelo fue sintetizado y presentado en inglés en Williamson (1983) y Taylor (1991). Fue aplicado también a la explicación de las crisis de los años 90`en Taylor (1998), Eatwell y Taylor (2000) y Frenkel (2002).
} 
A consecuencia de la apreciación cambiaria, la apertura comercial y la expansión de la demanda interna, las importaciones aumentan con rapidez y se amplía el déficit comercial. Asimismo, el déficit de cuenta corriente tiende a aumentar, más lentamente al principio y más rápidamente en adelante, a medida que se va acumulando deuda externa y aumenta el stock de capital extranjero invertido en la economía. Los precios relativos sesgan la inversión real hacia los sectores no comerciables. En consecuencia, en el balance en cuenta corriente, las crecientes rentas en moneda internacional de la inversión extranjera directa no tienen contrapartida en un aumento paralelo de las exportaciones.

La evolución de las cuentas externas y de las reservas de divisas definen un aspecto del ciclo. Hay un continuo aumento del déficit en cuenta corriente, mientras que los flujos de capital pueden sufrir cambios abruptos. En cierto momento el déficit de cuenta corriente es mayor que los ingresos de capital. Las reservas alcanzan entonces un máximo y luego se contraen, induciendo la contracción del dinero y el crédito. Sin embargo, el ciclo no está determinado exclusivamente por este elemento mecánico: la magnitud de los flujos de capital no es un dato exógeno. Las decisiones de portafolio de los agentes locales y externos con relación a la proporción de activos locales - la porción de la cartera del agente expuesta al riesgo del país o al riesgo cambiario - son afectadas por la evolución del balance de pagos y las finanzas.

La tasa de interés interna refleja los aspectos financieros del ciclo. Tiende a reducirse en la primera fase y aumenta en la segunda. Como la política cambiaria goza inicialmente de gran credibilidad, el arbitraje entre activos financieros y créditos locales y externos induce la reducción de la tasa en la primera fase. Tasas de interés bajas contribuyen a la expansión real y financiera. En este contexto se incrementa significativamente la fragilidad financiera (en el sentido de Minsky (1975)). En la segunda fase aumenta la tasa de interés y emergen episodios de iliquidez e insolvencia, primero como casos aislados y luego como crisis sistémica. ¿Cómo se explica el aumento de las tasas nominales y reales de interés?

Como el mercado financiero está abierto en ambas direcciones hay arbitraje entre activos locales y externos, como se mencionó. La tasa de interés en moneda local puede expresarse como la suma de la tasa internacional en dólares que confronta el país más la tasa de devaluación pautada por la regla cambiaria (cero en los casos de tipo de cambio fijo), más un residuo que responde por el riesgo cambiario y el riesgo financiero local. A su vez, la tasa internacional que confronta el país puede descomponerse en dos términos: la tasa de interés que paga el gobierno de Estados Unidos - esta es la tasa base del mercado financiero internacional - más un residuo que compensa el riesgo 
de la deuda local emitida en dólares. Salvo para algunos instrumentos de deuda excepcionales, el piso de esta compensación es la prima que pagan los bonos de deuda en dólares del gobierno nacional, la llamada prima de riesgo país.

La suma de la prima de riesgo cambiario más la prima de riesgo país - el precio agregado del riesgo de devaluación y el riesgo de default - es la principal variable de cuyo aumento resulta la tendencia creciente de la tasa de interés local. El persistente aumento del déficit en cuenta corriente - y a partir de cierto punto la tendencia contractiva de las reservas de divisas- reduce la credibilidad de la regla cambiaria, por un lado, mientras que, por otro lado, se incrementa la probabilidad de que la deuda emitida no sea honrada en tiempo y forma. El sostenimiento de la regla cambiaria y el servicio regular de las obligaciones externas requieren crecientes ingresos de capital. Por lo tanto, los precios de los riesgos tienden a aumentar. Altas primas de riesgo $y$, consecuentemente, altas tasas de interés, son necesarias para equilibrar los portafolios y atraer capital del exterior. La actividad económica se contrae y episodios de iliquidez e insolvencia contribuyen adicionalmente a reducir la credibilidad de la regla cambiaria. Esta dinámica probó ser explosiva en los casos examinados. Al final del proceso no hay tasas de interés suficientemente altas como para sostener la demanda de activos financieros locales. Hay corridas contra las reservas del Banco Central, que conducen finalmente al colapso de régimen cambiario. En los casos de los años noventa, el mercado se cierra generalmente para nuevas colocaciones cuando la prima de riesgo país alcanza cierto nivel.

Los pesos relativos de la prima de riesgo cambiario y de la prima de riesgo país han sido distintos en las experiencias de los años setenta y noventa. Esta diferencia está asociada con las distintas formas que asume el financiamiento externo en uno y otro momento. En los años setenta el financiamiento provenía principalmente de créditos de bancos internacionales. La prima de riesgo país era entonces la sobretasa por encima de la tasa de primera línea internacional cargada por bancos en sus créditos al país. El mercado secundario de deudas era insignificante. En ese contexto, en los casos de Argentina y Chile de los setenta, la prima de riesgo cambiario fue el principal determinante del aumento de la tasa de interés en la segunda fase del ciclo, mientras que la sobretasa de los bancos acreedores jugó un papel poco significativo. Esto puede explicarse por la conducta de los bancos. En tanto cada banco tiene ya colocada una porción de su cartera en activos del país, tiene interés en preservar su calidad y la capacidad de repago del deudor. La consideración de la cartera hundida influye en las decisiones acerca de los montos y el precio de los nuevos créditos. 
En cambio, en los años noventa la forma principal de financiamiento es la colocación de bonos y otros instrumentos de deuda en un mercado primario constituido por muchos y diversos actores. Los papeles de deuda emitidos se transan cotidianamente en un activo mercado secundario. La prima de riesgo país resulta de la cotización continua de los papeles en ese mercado. En los casos de los años noventa, el aumento de la prima de riesgo país - resultante de la caída del precio de los papeles de deuda del país en el mercado secundario global - es el principal motor del aumento de las tasas de interés en la fase contractiva del ciclo. El mercado de deudas de la etapa reciente de la globalización es más volátil que el mercado de créditos de los setenta. Está más sujeto a contagios y movimientos de manada.

\subsection{El déficit fiscal y la deuda pública}

El análisis presentado arriba destaca ciertos hechos estilizados presentes en todos los procesos que condujeron a las crisis que estamos considerando aquí. La descripción de los hechos estilizados se enfoca en la articulación de las finanzas y la economía real del país con el sistema financiero internacional. Hay retroalimentación positiva en la fase de auge y negativa en la fase de contracción. Puede observarse que en la descripción de la economía local no se analizan por separado el sector privado y el sector público. El déficit fiscal financiado con capitales externos está tácitamente incluido entre los destinos locales de los ingresos de capitales y consolidado con el déficit privado. La deuda externa del sector público es una parte de la deuda externa total del país y su evolución no se analiza por separado.

La explicación de esta perspectiva es simple: la sostenibilidad fiscal no ha jugado un papel destacable en la generación de las crisis de Chile de 1982, México de 1994-95, Argentina de 1995 y Brasil de 1998-99 (así como

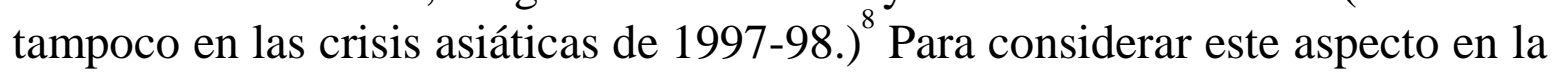
experiencia argentina reciente, abordaremos primero, en la sección siguiente, la información disponible sobre la evolución fiscal bajo la convertibilidad. Luego retornaremos, en la última parte de este trabajo, a las relaciones entre las cuentas fiscales y la crisis.

\footnotetext{
${ }^{8}$ Si el sector público tiene algún déficit a financiar y alguna deuda emitida, el aumento de la tasa de interés de la fase contractiva tiene a incrementar los déficit y a acelerar el aumento de las deudas, tanto del sector público como del sector privado. En los momentos cercanos a las crisis la administración de la deuda pública generó dificultades en México y Brasil. Pero este no es el punto. La cuestión se refiere al mecanismo determinante del aumento de los riesgos y la tasa de interés. Esto es, si la fuente de incertidumbre original se encuentra en la dinámica de las cuentas y necesidades de financiamiento públicas o se encuentra en la dinámica de las cuentas y necesidades de financiamiento externas. En Brasil y México no fueron los problemas fiscales los que indujeron la segunda fase del ciclo.
} 


\section{El desempeño fiscal bajo el régimen de convertibilidad}

Hemos señalado en la sección precedente que, con pocas excepciones ${ }^{9}$, en la mayor parte de las interpretaciones del colapso del régimen de caja de conversión instalado en Argentina en 1991 se identifica al desequilibrio fiscal como causa central, cuando no excluyente, de esa crisis.

Por cierto, no hay dudas de la presencia de un ostensible desbalance financiero del sector público en los tramos finales de ese esquema macroeconómico. Sin embargo, esa evidencia no habilita, por sí sola, una lectura causal. Nuestra propia interpretación de la forma de funcionamiento de ese régimen monetario, planteada en la sección precedente, entiende como principales problemas para la sustentabilidad del mismo a los derivados de la apreciación cambiaria y sus consecuencias sobre la vulnerabilidad externa de la economía.

En verdad, la evaluación del desempeño fiscal en la década de los noventa ha estado oscurecida por las serias limitaciones de los datos disponibles. No se cuenta, por ejemplo, con cifras oficiales consolidadas de las obligaciones financieras del sector público nacional previas a 1993. Tampoco con las relativas a la deuda provincial anterior a 1996, ni con datos completos de ingresos y gastos estatales (base devengado) para el sector público nacional, con anterioridad a 1994. Esto dificulta la caracterización de las condiciones iniciales de la década, complicando también, en consecuencia, la evaluación de lo acontecido entre los extremos del período.

Es un hecho conocido, además, que existe una discrepancia importante entre las cifras de desequilibrio fiscal y las variaciones de la deuda pública producidas en este lapso. Esta aparente inconsistencia entre las cifras de flujos y las variaciones de stocks es difícil de comprender y de resolver a partir de los datos publicados. En este trabajo hemos tratado, entre otros aspectos, de cerrar de la mejor forma posible esa brecha informativa, lo que resulta imprescindible a nuestro criterio para poder plantear un juicio razonablemente fundado sobre el desempeño fiscal de la Argentina en esa década crucial.

Presentamos aquí, por ejemplo, estimaciones de la deuda pública para todo el período, y también identificamos los principales factores que permiten

\footnotetext{
9 Calvo et al. (2002), por ejemplo, desplazan el centro de atención hacia los efectos de la volatilidad de los flujos de capitales. Hausmann y Velasco (2002) tampoco entienden que el desbalance financiero de las cuentas públicas haya tenido un papel decisivo. Lo atribuyen, además, a los efectos de la reforma previsional privatista llevada a cabo en 1994 y no a una política fiscal fuera de control.

Cf. Damill, Frenkel y Maurizio (2002). Esta visión caracteriza también a algunos trabajos referidos más específicamente a la cuestión fiscal, como el elaborado por Gaggero y Gómez Sabaini (2002).
} 
explicar las diferencias entre los datos de flujos (el déficit de las cuentas públicas) y las variaciones de stocks (es decir, de la deuda del sector estatal). Una explicación de las cuestiones metodológicas involucradas y de los procedimientos seguidos para construir las distintas series se incluye en anexo al final de este trabajo. A partir de estos datos delineamos, asimismo, un análisis de la evolución de las cuentas fiscales y de la deuda pública en el decenio, de la que se desprenden conclusiones contrastantes, en varios aspectos, con las que caracterizan a la interpretación más difundida de la crisis.

\subsection{El desequilibrio fiscal en el largo plazo}

Para evaluar el desempeño fiscal en la década comenzamos por situarla en una perspectiva de más largo plazo. Lo hacemos considerando los datos del cuadro siguiente.

Cuadro 1. Resultado fiscal consolidado (Nación más Provincias y Ciudad de Buenos Aires)

promedios por período, en porcentaje del PIB

\begin{tabular}{|c|c|c|c|c|c|}
\hline Período & $\begin{array}{c}\text { Resultado } \\
\text { Primario sin } \\
\text { privatizaciones }\end{array}$ & $\begin{array}{c}\text { Resultado } \\
\text { Primario }\end{array}$ & Intereses & $\begin{array}{c}\text { Resultado Total } \\
\text { sin } \\
\text { privatizaciones }\end{array}$ & $\begin{array}{c}\text { Resultado } \\
\text { Total }\end{array}$ \\
\hline $1961-1970$ & $-3,4$ & $-3,4$ & 0,7 & $-4,0$ & $-4,0$ \\
$1971-1980$ & $-6,0$ & $-6,0$ & 1,0 & $-7,0$ & $-7,0$ \\
$1981-1990$ & $-5,1$ & $-5,1$ & 2,0 & $-7,0$ & $-7,0$ \\
$1991-2000$ & $-0,4$ & 0,1 & 2,2 & $-2,6$ & $-2,1$ \\
\hline
\end{tabular}

Fuente: Gaggero (2003).

Esas estimaciones muestran con nitidez que el desbalance financiero fiscal se atenuó notablemente en los años noventa. Se alcanzó en promedio una situación equilibrada de las cuentas públicas "antes de intereses" (es decir, un resultado primario balanceado), lo que implica un considerable ajuste de más de 5 puntos del PIB en comparación con lo observado en los dos decenios precedentes.

El resultado global también mejoró en cifras de ese orden de magnitud. Para el conjunto de la década, en promedio, el déficit se asemeja además a la carga de intereses de la deuda, algo superior a $2 \%$ del PIB. 


\subsection{El resultado fiscal bajo el régimen de caja de conversión}

Esos promedios para la década de los noventa resultan, sin embargo, de comportamientos bastante diferentes a lo largo de la misma. Pueden identificarse, a grandes rasgos, tres etapas marcadamente distintas: la fase inicial (1991-94), un período intermedio anterior a la depresión (1995-97), y el lapso final que desembocaría en la crisis del régimen macroeconómico. Los principales hitos que separan esas fases son la reforma previsional de 1994, primeramente, y en segundo término el inicio, en 1998, de la contracción económica que se extendería hasta comienzos de 2002, y que coincide con la crisis rusa de aquel año.

\section{Gráfico 1. Déficit fiscal en los años noventa.}

base devengado, como \% del PIB.

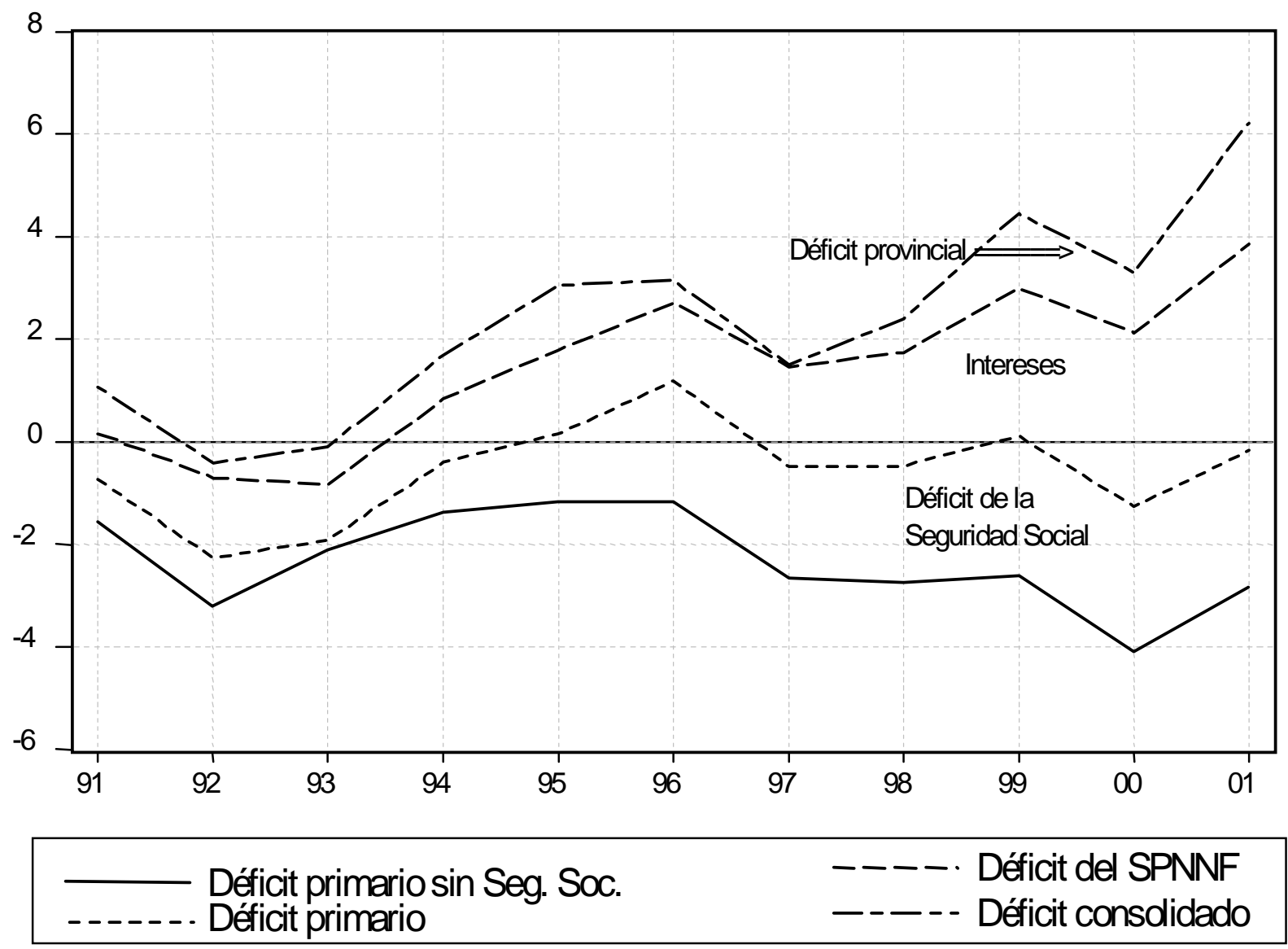

Fuente: Elaboración propia a partir de datos del Ministerio de Economía y de Cetrángolo et al. (2000) para el período anterior a 1994. 
Considerando el panorama macroeconómico, la primera etapa fiscal se corresponde con la fase de estabilización de precios y de fuerte expansión del producto, alimentada por ingresos importantes de capitales. La segunda se inicia con la breve recesión de 1995 provocada por el efecto tequila, a la que sigue una rápida expansión. Luego, el tercer período está dominado por un cuadro depresivo deflacionario en todo su desarrollo.

Describimos enseguida los principales hechos relativos al desempeño fiscal en esas fases a partir del gráfico $1 \mathrm{y}$ de los cuadros 2.a y 2.b.

Cuadro 2.a. Resultados fiscales en la década de los noventa base devengado, en millones de dólares, a precios corrientes

\begin{tabular}{|c|c|c|c|c|c|c|c|}
\hline Período & $\begin{array}{l}\text { Resultado } \\
\text { Primario sin } \\
\text { Seguridad } \\
\text { Social } \\
\text { (1) }\end{array}$ & \begin{tabular}{|} 
Resultado \\
de la \\
Segurida \\
d Social \\
$(2)$
\end{tabular} & $\begin{array}{c}\text { Resultado } \\
\text { Primario } \\
\text { (3) }\end{array}$ & $\begin{array}{c}\text { Pagos de } \\
\text { Intereses } \\
\text { (4) }\end{array}$ & $\begin{array}{c}\text { Resultado } \\
\text { del Sector } \\
\text { Público } \\
\text { Nacional } \\
\text { (5) }\end{array}$ & $\begin{array}{c}\text { Resultado } \\
\text { de las } \\
\text { Provincias } \\
\text { (6) }\end{array}$ & $\begin{array}{l}\text { Resultado } \\
\text { del Sector } \\
\text { Público } \\
\text { Consolidado } \\
\text { (7) }\end{array}$ \\
\hline $\begin{array}{c}\text { Acumulado } \\
1991-94\end{array}$ & 18154 & -6495 & 11658 & 10654 & 1004 & -6116 & -5112 \\
\hline $\begin{array}{c}\text { Acumulado } \\
1995-97\end{array}$ & 13967 & -16193 & -2226 & 14036 & -16262 & -4553 & -20815 \\
\hline $\begin{array}{c}\text { Acumulado } \\
1998-01 \\
\end{array}$ & 34851 & -29656 & 5195 & 35271 & -30076 & -15759 & -45835 \\
\hline $\begin{array}{c}\text { Acumulado } \\
1991-01\end{array}$ & 66972 & -52345 & 14627 & 59960 & -45333 & -26428 & -71762 \\
\hline
\end{tabular}

Nota:

(2) No corresponde exactamente al déficit del sistema de seguridad social público, sino a la diferencia entre los pagos previsionales reflejados en las cuentas del Gobierno Nacional y los ingresos propios de ese sistema, derivados de aportes patronales y de contribuciones jubilatorias sobre el salario. Ese sistema también recibe ingresos a partir de otras fuentes, como una parte de la recaudación del impuesto a las ganancias, etc.

(3) $=(1)+(2)$.

(5) $=(3)-(4)$.

$(7)=(5)+(6)$.

Fuente: elaboración propia a partir de datos del Ministerio de Economía, y de Cetrángolo et al. (2000) para 1991-94. 
Cuadro 2.b. Resultados fiscales en la década de los noventa

base devengado, promedios por período, en porcentaje del PIB

\begin{tabular}{|l|r|r|r|r|r|r|r|}
\hline Período & $\begin{array}{c}\text { Resultado } \\
\text { Primario } \\
\text { sin } \\
\text { Seguridad } \\
\text { Social }\end{array}$ & $\begin{array}{c}\text { Resultado } \\
\text { Primario }\end{array}$ & $\begin{aligned} \text { Pagos de } \\
\text { Intereses }\end{aligned}$ & $\begin{array}{r}\text { Resultado } \\
\text { del } \\
\text { Sector } \\
\text { Público } \\
\text { Nacional }\end{array}$ & $\begin{array}{c}\text { Resultado } \\
\text { del Sector } \\
\text { Público } \\
\text { Consolidado } \\
(1)\end{array}$ & $\begin{array}{c}\text { Ingresos por } \\
\text { privatización } \\
\text { de empresas } \\
\text { públicas } \\
(2)\end{array}$ & $\begin{array}{c}\text { Resultado } \\
\text { Consolidado sin } \\
\text { privatizaciones } \\
(3)\end{array}$ \\
\hline $\begin{array}{l}\text { Promedio } \\
1991-94 \\
\text { Promedio } \\
1995-97\end{array}$ & 2,07 & 1,33 & 1,20 & 0,13 & $-0,56$ & 0,60 & $-1,16$ \\
$\begin{array}{l}\text { Promedio } \\
1998-01\end{array}$ & 1,66 & $-0,29$ & 1,70 & $-1,99$ & $-2,56$ & 0,49 & $-3,05$ \\
\hline $\begin{array}{l}\text { Promedio } \\
1991-01\end{array}$ & 2,07 & 0,45 & 3,13 & $-2,68$ & $-4,09$ & 0,37 & $-4,46$ \\
\hline
\end{tabular}

(3) $=(1)-(2)$

Fuente: idem cuadro 2.a.

\subsubsection{La fase inicial (1991-94)}

Los tempranos años noventa atestiguaron una muy significativa mejora de las cuentas públicas. La etapa inmediatamente anterior, en la que la economía atravesó varios episodios de marcada inestabilidad e hiperinflación, había licuado los ingresos fiscales reales. Estos se recompusieron notablemente como resultado de la estabilización de precios posterior al lanzamiento del plan de convertibilidad, y también de la rápida recuperación económica que se había iniciado un poco antes, en 1990, y que el éxito estabilizador apuntaló. Por otra parte, la estabilidad macroeconómica facilitó las tareas de la administración tributaria, área en la que se produjeron importantes mejoras en el período, las que operaron en el mismo sentido ${ }^{11}$. Las cifras de presión tributaria incluidas más adelante, en el cuadro 4, atestiguan la significativa recomposición de la capacidad recaudatoria en este lapso.

Como puede verse en el gráfico 1, el sector público consolidado alcanzó un pequeño superávit en el bienio 1992-93. Para toda esta fase inicial el resultado promedio fue, sin embargo, negativo, aunque promedió apenas $0,56 \%$ del producto (cuadro 2.b).

Estos fueron, por otro lado, los años en que el proceso de privatizaciones iniciado en 1990 adquirió mayor envergadura. Si se dejan de lado los ingresos de recursos líquidos que el sector público obtuvo de esta fuente, el desbalance

11

Gaggero y Gómez Sabaini (2002), Cetrángolo y Jiménez (2003). 
asciende a $1,16 \%$ del PIB. Las cifras muestran, por otro lado, que aproximadamente la mitad de ese desequilibrio se debió al rojo de las finanzas provinciales.

Ese resultado promedio puede descomponerse, a partir de las cifras del cuadro $2 \mathrm{~b}$, en un superávit primario del sector público nacional (SPN) de algo más de $2 \%$ del PIB sin considerar el resultado del sistema de seguridad social (SSS) ${ }^{12}$, un déficit de $0,74 \%$ del PIB del SSS, y pagos de intereses de $1,2 \%$. A eso debe agregarse el déficit provincial $(-0,69 \%)$ para obtener el resultado consolidado.

\subsubsection{La reforma previsional}

En 1994 el sistema previsional, hasta entonces consistente en un híbrido que combinaba un mecanismo de reparto con proporcionalidad (vinculación de los beneficios jubilatorios con el salario de los activos) fue reformado, dando lugar a la coexistencia de un sistema privado de capitalización con un sistema público en el que permanecían los trabajadores ya retirados y parte de los activos que optaran por tal alternativa.

No examinaremos aquí en detalle esa reforma. ${ }^{13}$ El punto más importante en relación con los resultados fiscales a lo largo de los años noventa es el impacto sobre el desequilibrio del subsistema previsional público. Puesto que muchos aportantes se trasladaron (y con ellos sus aportes) hacia el nuevo sistema privado, los ingresos de la seguridad social estatal declinaron muy sensiblemente. El aumento de las necesidades de financiamiento del SSS a partir de 1994 es ilustrado muy claramente en el gráfico $1 .^{14}$

\subsubsection{La fase intermedia (1994-1997)}

Con la reforma previsional se inicia otra fase de la evolución fiscal de los noventa. Es también en este período intermedio que se comienza a recurrir a las que genéricamente se ha denominado "devaluaciones fiscales": medidas destinadas a reducir la carga tributaria (sobre los sectores productores de bienes transables, principalmente) con el fin de compensar los problemas derivados de la apreciación real del peso, un rasgo congénito del régimen de caja de conversión.

\footnotetext{
12 Superávit que se reduce a alrededor de $1,47 \%$ si no se toman en cuenta los ingresos por privatizaciones.

13 Un análisis de la misma puede encontrarse en Cetrángolo (1994).

14

La definición del desequilibrio de la seguridad social reflejado en el gráfico es la misma que se señala en la nota (2) del cuadro 2.a.
} 
Como consecuencia de estos factores, la pérdida de recursos del SSS y la devaluacion fiscal, el déficit se incrementa. Lo hace a pesar de que en 1995, luego del shock externo derivado de la crisis mexicana, se vive la primera experiencia importante, en los años noventa, de políticas fiscales pro-cíclicas. El gobierno incrementa la tasa del IVA en ese año, junto con otras medidas dirigidas a paliar el efecto de la recesión sobre la recaudación tributaria.

En promedio, el desbalance financiero fiscal se eleva en alrededor de 2 puntos del PIB en comparación con la etapa anterior. Pero, según puede deducirse de las cifras del cuadro 2.b, el superávit primario del SPN, sin seguridad social, apenas declina en $0,4 \%$ del producto.

El peso principal en el deterioro de las cifras consolidadas lo tiene el déficit del SSS, que aumenta en el equivalente a 1,2\% del PIB aproximadamente. Es decir que un $60 \%$ del incremento del desbalance fiscal se explica por la evolución del sistema previsional público nacional (mientras que casi 25\% corresponde al aumento de la carga de intereses sobre la deuda). Obsérvese, por otra parte, que en esta etapa el desequilibrio de las provincias está en realidad cayendo (baja a $0,57 \%$ del PIB en promedio, en esta fase), alcanzándose una situación equilibrada en 1997, como muestra el gráfico 1.

\subsubsection{La deuda pública antes de la depresión}

Para completar la descripción de la evolución fiscal que estamos planteando aquí, desde una perspectiva macroeconómica, es imprescindible hacer referencia a la evolución de la deuda.

Como ya se indicó, hay una importante discrepancia entre las cifras relativas al endeudamiento estatal a lo largo de los años noventa y lo que podría deducirse a partir de las cifras del déficit consolidado.

En el cuadro 5, incluido más abajo, cuantificamos esa discrepancia para las tres fases que estamos caracterizando, e identificamos además los principales factores que la explican.

Como se ve, la mayor discrepancia se concentra justamente en la primera etapa, hasta 1994. En ella las obligaciones financieras del gobierno argentino y de las provincias aumentaron alrededor de 22 mil millones de dólares por encima de lo que permitiría explicar el desequilibrio financiero del sector público consolidado. Ello a pesar de que en este período el rescate de títulos a través de las privatizaciones superó los 7100 millones de dólares, y hubo una quita de capital, con la firma del Plan Brady, que se ha estimado en poco más de 2300 millones de esa moneda.

Sin embargo, como muestra el cuadro mencionado, el grueso de esa discrepancia deriva del reconocimiento, en estos primeros años de la 
convertibilidad, de deudas (previsionales y con proveedores del estado) devengadas en su gran mayoría en períodos anteriores.

Aún así, es muy destacable el hecho, que el gráfico 2 pone en evidencia, de que la deuda pública, medida como porcentaje del PIB, se mantiene básicamente estable en esta etapa, por debajo de 30\% (para la deuda total), y de $25 \%$ en el caso de la deuda externa. Esta última en realidad tiende a declinar, en parte como resultado de la apreciación cambiaria y también como consecuencia del rápido crecimiento del producto.

En síntesis, la fase 1991-1994 se caracterizó por una muy fuerte mejoría de las cuentas públicas y por la absorción no traumática de un gran volumen de deuda generada en gran medida en otros períodos, es decir, por una normalización de pasivos, muchos de ellos litigiosos. Si algo parece claro de estas cifras, en especial de las volcadas en el gráfico 2, es que no había signo alguno de insostenibilidad fiscal hacia 1994, cuando la economía es alcanzada por el shock externo derivado de la crisis de México.

En la etapa siguiente, la proporción deuda-producto da un salto ascendente. Pero como se ve también en el gráfico 2, el mismo se concentra en 1995. Es en parte un efecto de la recesión (que por sí sola incrementaría la relación deuda producto), pero refleja principalmente el paquete de ayuda externa articulado por el FMI, que permitió dejar rápidamente atrás el episodio de contracción y crisis financiera que siguió al Tequila.

Como la ilustración también sugiere, una vez superado ese episodio, en la fase expansiva que le siguió (1996-97), la relación entre la deuda pública total y el PIB parecía tender a estabilizarse nuevamente, y en un nivel bajo en cualquier comparación internacional: próximo a 35\%. La deuda externa incluso se reduce, en forma leve, como proporción del producto.

Nuevamente, y a pesar del aumento del déficit corriente y del desbalance del sistema previsional público, la evidencia parece distar mucho de sugerir un riesgo de insostenibilidad de naturaleza fiscal, hacia 1997, antes del inicio de la depresión.

\subsubsection{La depresión (1998-2001)}

En casi todos los planos, el panorama que hemos descrito hasta aquí cambia sustancialmente luego de ese último año, en especial a partir de la crisis rusa

\footnotetext{
15

La apreciación cambiaria tendió a reducir el cociente deuda producto, en la medida en que una elevada fracción de las obligaciones financieras del estado se encontraba denominada en moneda extranjera. En este punto, la fragilidad externa y la fragilidad financiera fiscal están muy directamente vinculadas, puesto que los ingresos fiscales son en moneda nacional.
} 
de agosto de 1998, cuyo impacto da inicio a una contracción económica que resultaría inusualmente prolongada.

El gráfico 1 y el cuadro 3 , que se presenta a continuación, ayudan a comprender algunos rasgos centrales de la evolución fiscal en esta etapa.

En primer lugar, el déficit del sector público consolidado ingresa en una trayectoria marcadamente ascendente, que lo llevaría a rondar los 6 puntos del PIB en 2001. Ello a pesar de que en esta larga fase hubo varias rondas (a fines de 1998, a fines de 1999 y en 2001) de políticas fiscales contractivas, procíclicas, instrumentadas con la intención de revertir esa tendencia. ${ }^{16}$

Las cifras del cuadro 3 nos permiten poner la evolución fiscal en perspectiva, comparando el desequilibrio promedio del período depresivo con 1994, el último año de la fase inicial de los años noventa.

El déficit anual promedio de 1998-2001 (que, según el criterio de lo devengado, ascendió a 11458 millones de dólares), resultó superior al registrado en 1994 en 7112 millones de esa moneda.

¿Dónde se originó ese incremento? Como se ve, la cuota mayor de la explicación corresponde al aumento de los pagos de intereses (+6784 millones), y en segundo lugar a la ampliación de la brecha del sistema de seguridad social (+4867). Una cifra relativamente menor (+592 millones) es explicada por el desbalance provincial, aunque es cierto que este seguía una trayectoria creciente, que se puede constatar por ejemplo en el gráfico 1.

El cuadro también pone en evidencia que las políticas fiscales pro-cíclicas, si bien inadecuadas, no fueron inefectivas: generaron un sustantivo incremento del superávit primario (sin seguridad social), de más de 5000 millones de dólares, en promedio anual. Aunque, como ya señalamos, eso no fue suficiente para compensar el aumento de los intereses y del desbalance previsional.

El comportamiento explosivo de la cuenta de intereses de la deuda se observa nítidamente en el cuadro 4. El peso de los intereses sobre los recursos tributarios, que ya había aumentado algo luego de 1994, comienza una vertiginosa carrera ascendente después de 1996. En 2000, antes del desenlace de la crisis, ese cociente se acercaba al $19 \%$, duplicando el valor que había tenido a mediados de la década. Eso se debió en parte a la reducción de los ingresos tributarios por la recesión. Pero sustancialmente, se originó en la suba de la tasa de interés promedio sobre la deuda pública total. Esa tasa fue estimada aproximadamente mediante el cociente entre los pagos anuales de intereses y el stock total de obligaciones a fines del año anterior, y se incluye

${ }^{16}$ Gaggero (2003). 
Cuadro 3. Comparación del déficit público promedio de 1998-2001 con el de 1994

base devengado, en millones de dólares, a precios corrientes

\begin{tabular}{|l|r|}
\hline (1) Variación del déficit consolidado & +7112 \\
\hline (2) Variación del déficit de la Seguridad Social & +4867 \\
(3) Variación del déficit primario del S.Público Nacional sin Seg. Soc. & -5131 \\
(4) Variación del déficit primario provincial & +592 \\
(5) Variación de los pagos de intereses del S.Público consolidado & +6784 \\
\hline
\end{tabular}

Fuente: elaboración propia a partir de datos del Ministerio de Economía y Cetrángolo et.al. (2000).

también en el cuadro 4. La tasa media de interés pasó de 5,8\% en 1996 a 9,4\% en 2001. Debe tomarse en cuenta, además, que cierta proporción de la deuda se encontraba pactada a tasa fija. De modo que la suba de las tasas de interés en el segmento a tasa variable fue extremadamente fuerte.

\subsubsection{La deuda pública en la fase de depresión}

Impulsada por la suba de la prima de riesgo país (con la que se correlaciona muy estrechamente en el período 1997-2001), la trayectoria ascendente de la tasa de interés a la que se ha hecho referencia se refleja en el déficit consolidado, como ya se indicó, y también el sendero explosivo que asume entonces la deuda pública (gráfico 2).

La descripción que hemos planteado hasta aquí muestra que se trató, sustancialmente, de un problema financiero, de una "trampa de endeudamiento" en un contexto de turbulencia financiera externa que gravitó negativamente sobre las primas de riesgo. En 1997, antes del impacto de la crisis rusa, el déficit consolidado era inferior a $2 \%$ del PIB (gráfico 1), venía declinando, y la deuda pública total no superaba el 35\% del producto. Más allá de las evidencias acerca de cierto aflojamiento de la disciplina de la Tesorería, y especialmente en las provincias, hacia la fase final del gobierno de Menem, el cuadro que se ha descrito no sugiere que el camino hacia la crisis haya sido el resultado de una política fiscal discrecional y fuera de control. Por el contrario, ya hemos visto que las políticas activas de carácter pro-cíclico consiguieron generar un superávit primario importante (sin considerar el desequilibrio de la seguridad social), muy superior al de los tempranos años noventa. Estas políticas, que alimentaron, por otro lado, la continuidad del cuadro deflacionario, no bastaron para poner freno el crecimiento de la deuda. 
Cuadro 4. Presión tributaria del sector público consolidado y peso de los intereses de la deuda total del sector público consolidado. en porcentajes

\begin{tabular}{|c|c|r|r|}
\hline Año & $\begin{array}{c}\text { Presión } \\
\text { Tributaria } \\
(\% \text { del PIB) } \\
(1)\end{array}$ & $\begin{array}{c}\text { Tasa media de } \\
\text { interés sobre la } \\
\text { deuda pública }(\%) \\
(2)\end{array}$ & $\begin{array}{c}\text { Intereses sobre } \\
\text { ingresos } \\
\text { tributarios }(\%) \\
(3)\end{array}$ \\
\hline 1991 & 18,8 & nd & 5,6 \\
1992 & 20.8 & 6,6 & 8,3 \\
1993 & 21,3 & 5,0 & 6,0 \\
1994 & 21,1 & 5,5 & 6,9 \\
1995 & 20,9 & 6,1 & 9,2 \\
1996 & 19,6 & 5,8 & 9,7 \\
1997 & 21,0 & 6,7 & 10,9 \\
1998 & 21,4 & 7,6 & 12,2 \\
1999 & 21,4 & 8,3 & 15,9 \\
2000 & 21,9 & 8,9 & 18,5 \\
2001 & 21,1 & 9,4 & 23,4 \\
\hline
\end{tabular}

(1) Según los datos base caja. Incluye las contribuciones al sistema previsional público.

(2) Estimada como el cociente entre los pagos de intereses de cada año y el stock de deuda al final del año anterior.

(3) Los ingresos tributarios incluyen las contribuciones al sistema previsional público.

Fuente: elaboración propia a partir de datos de Gaggero (2003) y del Ministerio de Economía.

Además, como se observa en el gráfico 2, el crecientemente dificultoso acceso al financiamiento externo en ese contexto internacional desfavorable hizo que ganara peso, en forma progresiva, el endeudamiento interno del sector público (con el sistema previsional privado y con los bancos, principalmente). Mientras tanto, la deuda externa tendía a estabilizarse, aunque la relación deuda externa-producto seguía ascendiendo, moderadamente, sobre todo por la declinación del PIB. El cociente entre la deuda del sector público consolidado y el producto superaría el 55\% en 2001. Había aumentado 20 puntos en sólo 4 años. 
Gráfico 2 Evolución de la deuda del Sector Público consolidado como porcentaje del PIB

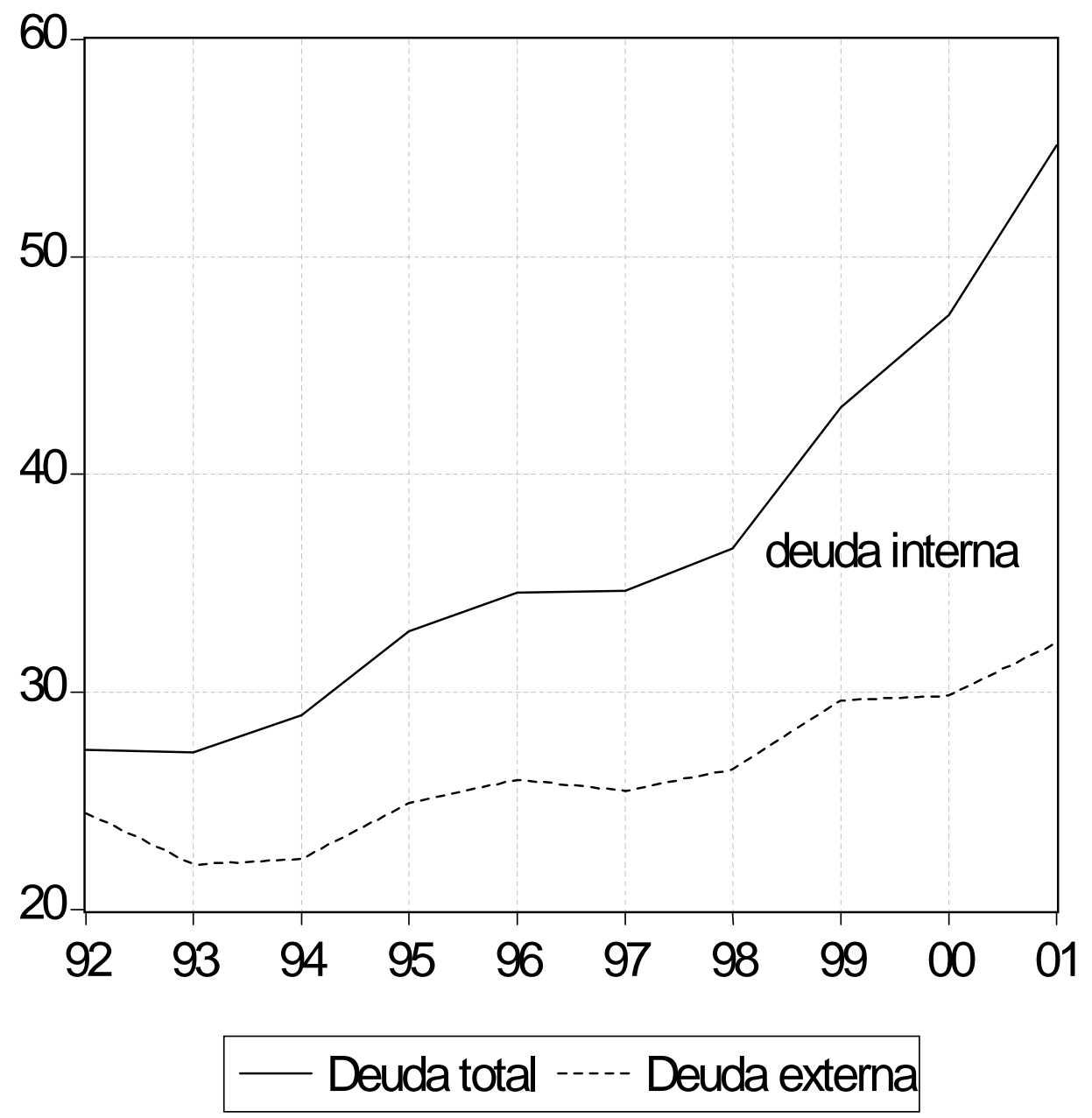

Fuente: Elaboración propia a partir de datos del Ministerio de Economía.

Nota: cada observación corresponde al promedio de los saldos de deuda de comienzo y fin del año correspondiente, dividido por el PIB a precios corrientes del mismo año. 
Cuadro 5. Déficit fiscal y variación de la deuda pública

en millones de dólares a precios corrientes

\begin{tabular}{|c|c|c|c|c|c|c|c|c|c|c|}
\hline Período & \begin{tabular}{|c|} 
Déficit del \\
Sector \\
Público \\
Consolidado \\
(1)
\end{tabular} & \begin{tabular}{|c|} 
Variación \\
de la \\
Deuda \\
Pública \\
Bruta \\
$(2)$
\end{tabular} & Discrepancia & \begin{tabular}{|c|} 
Deudas \\
de otros \\
períodos \\
$(4)$
\end{tabular} & \begin{tabular}{|c|} 
Intereses \\
capitalizados \\
$(5)$
\end{tabular} & $\begin{array}{c}\text { Diferencias } \\
\text { de cambio }\end{array}$ & \begin{tabular}{|c|}
$\begin{array}{c}\text { Variación } \\
\text { de activos }\end{array}$ \\
(7)
\end{tabular} & \begin{tabular}{|c|} 
Quita del \\
Plan Brady \\
$(8)$
\end{tabular} & \begin{tabular}{|c} 
Rescate de \\
títulos de \\
deuda por \\
privatizaciones \\
(9)
\end{tabular} & \begin{tabular}{|c|} 
Otros \\
factores \\
$(10)$
\end{tabular} \\
\hline $\begin{array}{c}1992- \\
1994\end{array}$ & 3247 & 25094 & 21847 & 22859 & 2255 & $\begin{array}{l}-599 \\
\end{array}$ & 3205 & 2323 & 7111 & 3561 \\
\hline $\begin{array}{c}1995- \\
1997\end{array}$ & 20815 & 22659 & 1844 & 3892 & 3135 & -3381 & 2842 & 0 & 40 & -4604 \\
\hline $\begin{array}{c}1998- \\
2001\end{array}$ & 45835 & 52817 & 6982 & 5947 & 1624 & -5665 & -152 & 0 & 0 & 5228 \\
\hline Total & 69897 & 100570 & 30673 & 32698 & 7014 & -9645 & 5895 & 2323 & 7151 & 4185 \\
\hline
\end{tabular}

(2) No incluye la deuda del Banco Central.

(2) $-(1)=(3)$

$(3)=(4)+(5)+(6)+(7)-(8)-(9)+(10)$

(8) Incluye, en 1992-94, restando, 2323 millones de dólares correspondientes a la estimación de la quita generada por el Plan Brady.

Fuente: elaboración propia a partir de datos del Ministerio de Economía, Melconian et.al. (1997), Cetrángolo et.al. (2000) y Teijeiro (1996).

Nota: la variación de la deuda del Banco Central con los organismos multilaterales, no incluida aquí, fue de 2771 millones de dólares entre 1991 y 2000. En el año de la crisis, 2001, dio un salto de 8867 millones, debido en buena medida al financiamiento obtenido del FMI para recomposición de reservas. Esa deuda no se incluye aquí porque no tiene origen ni uso fiscal. 


\subsubsection{El comportamiento del gasto del sector público consolidado}

En las secciones precedentes hemos examinado principalmente la evolución del desequilibrio financiero fiscal y de sus aspectos financieros. Para completar ese análisis incluimos ahora la información agregada sobre la evolución del gasto público a lo largo de la década de los noventa.

La relevancia de este aspecto resalta porque algunas de las visiones que ponen el eje en la cuestión fiscal como la matriz de la crisis en Argentina enfatizan el supuestamente muy fuerte incremento del gasto estatal como la verdadera raíz del problema.

Gráfico 3. Gasto primario del Sector Público Consolidado base devengado, en términos per capita y a precios constantes, y PIB per capita $(1991=100)$

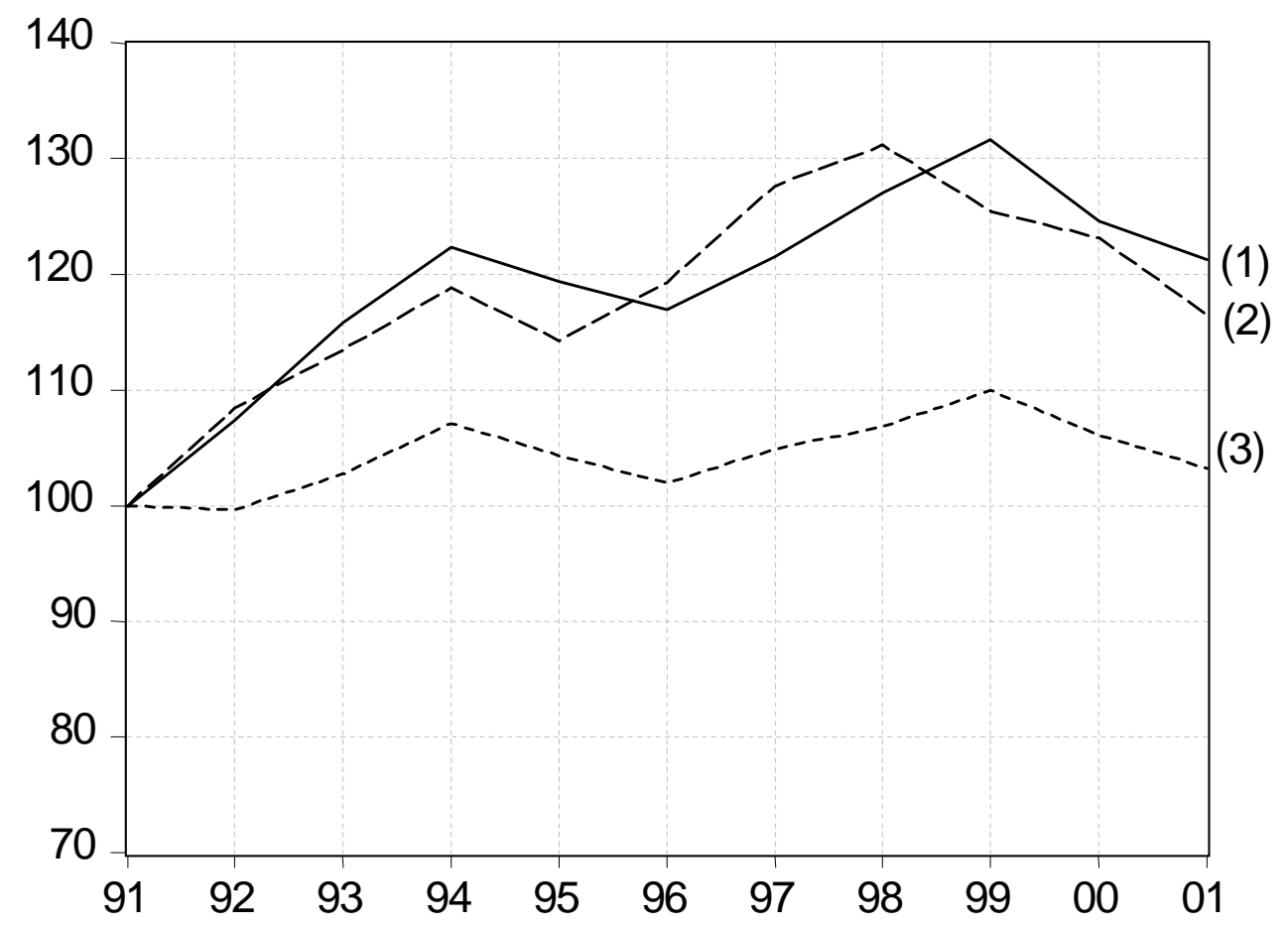

(1) Gasto primario deflactado por el Indice de precios implícitos del PIB.

(2) PIB per capita a precios constantes.

(3) Gasto primario deflactado por el IPC

Nota: estas series de gasto público incluyen el correspondiente a Obras Sociales, tanto en el nivel provincial como nacional, así como las cajas previsionales provinciales no transferidas, conceptos no incluidos en las cifras de la Secretaría de Hacienda, lo que resulta en un guarismo mayor para el gasto total (diferencia que alcanza, en el año 2000, a aproximadamente 3 puntos porcentuales del PIB).

Fuente: Elaboración propia a partir de datos de la Dirección Nacional de Gastos Sociales Consolidados. 
El gasto público se incrementó fuertemente entre los extremos de la década. Como se analizara en la sección precedente, eso se debió en buena medida al fuerte aumento de las tasas de interés sobre la deuda pública en la segunda mitad del decenio. Sin embargo, si se considera el gasto primario, que refleja más directamente los impulsos de política fiscal, puede verse que su incremento bajo la convertibilidad dista de ser explosivo. El gráfico 3, incluido más abajo, presenta las cifras correspondientes, para el sector público consolidado, en términos per capita y en moneda constante. Se incluye también la serie correspondiente al producto bruto interno per capita.

Lo primero que se observa en esas series es el comportamiento definidamente pro-cíclico del gasto público primario, que acompaña a la evolución del producto per capita a lo largo de los dos ciclos experimentados en los noventa, aunque los puntos de inflexión no coinciden exactamente con los del PIB. Hay una fase inicial de aumento de las erogaciones estatales por habitante, paralela a la fuerte expansión económica de inicios de la década. Luego se registra una declinación a mitad del decenio, coincidentemente con la recesión de 1995, desatada por el efecto tequila. Hay una recuperación posterior y una nueva declinación a fin de período.

El comportamiento del gasto primario deflactado por el índice de precios combinados muestra un comportamiento que se asemeja estrechamente al del PIB per capita. Esa serie de gasto alcanza un valor de 121 en 2001 (con base 100 en 1991). Ese aumento corresponde a una tasa de 1,9\% anual, levemente superior a la del PIB por habitante, que en ese mismo lapso creció a una tasa media de $1,5 \%$.

Por otra parte, si se deflacta el gasto primario por el índice de precios al consumidor, el nivel de 2001 es casi el mismo, apenas 3\% más elevado que el registrado en 1991.

En el gráfico 4 presentamos las cifras de gasto primario del Sector Público Consolidado junto con las correspondientes al gasto total, medidas como proporción del PIB.

Se observa que el gasto primario oscila a lo largo de la década en torno a una media de 26,6\% del PIB. Si bien aumenta en la fase depresiva iniciada en 1998, al final de ese período alcanzaba a $27,5 \%$ del producto, apenas $0,9 \%$ de punto por sobre la media de la década, y aproximadamente en el mismo nivel registrado en 1995. El gasto total presenta, en cambio, un comportamiento alcista mucho más definido, debido a la suba de las tasas de interés y a la consecuente dinámica explosiva de la deuda a partir de 1998, que se ha analizado más arriba. La media de la década es, en este caso, equivalente a 29,4\% del PIB, pero en 2001 se encontraba 3,4\% del producto por encima de 
esa cifra, alcanzando un valor de $32,81 \%$ en términos del producto total, guarismo que es, además, 4,55 puntos más elevado que el de 1991.

Gráfico 4. Gasto primario y gasto total del Sector Público Consolidado sobre PIB, y sus líneas de tendencia

en porcentajes

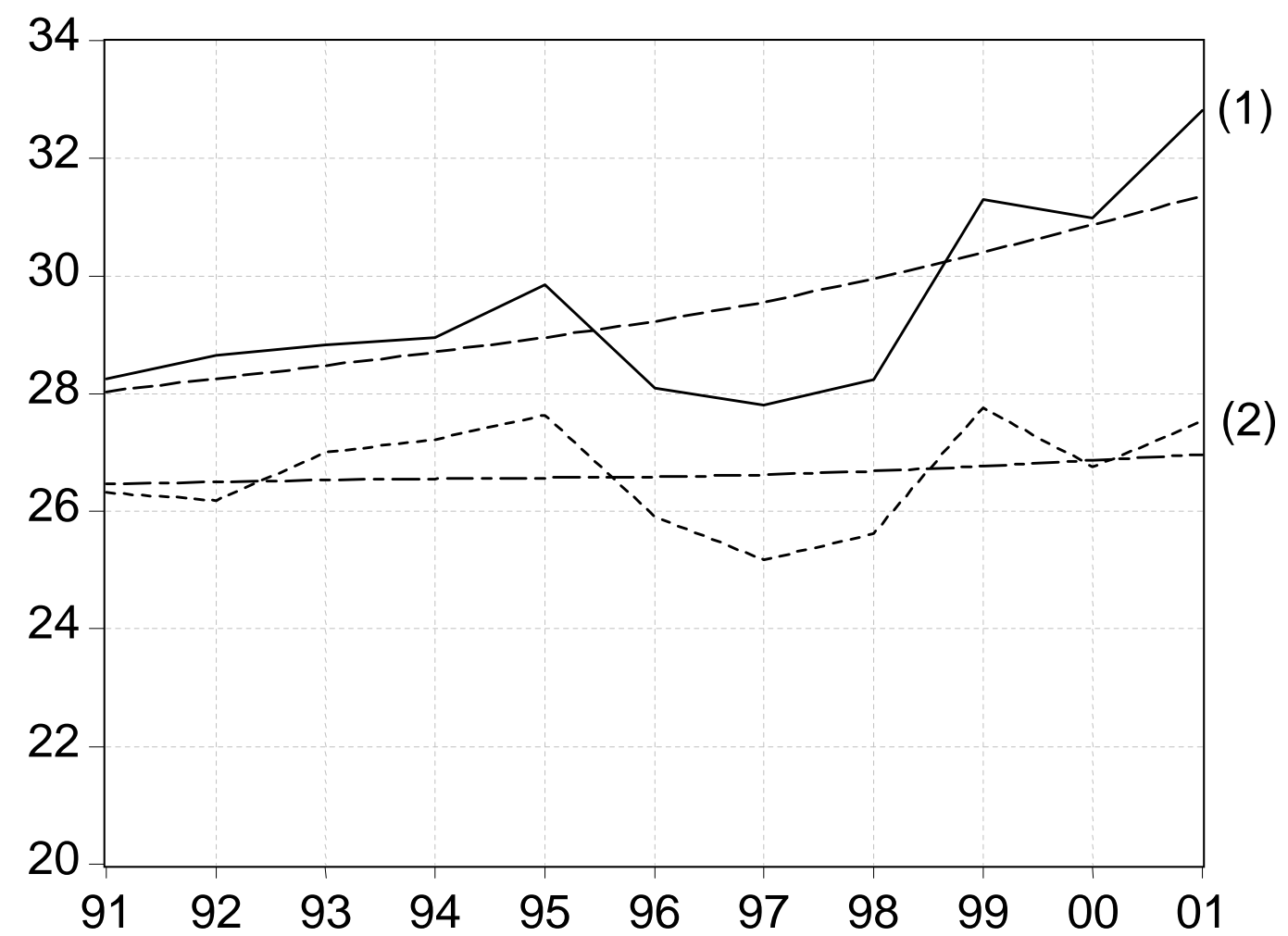

(1) Gasto total

(2) Gasto primario

Nota: estas series de gasto público incluyen el correspondiente a

Obras Sociales, tal como se indica al pie del gráfico 3.

Fuente: Elaboración propia a partir de datos de la Dirección Nacional de Gastos Sociales Consolidados.

\section{Las cuentas fiscales y la crisis: reflexiones finales}

Hemos señalado más arriba, en la segunda sección del trabajo, que en varios de los episodios de crisis que consideramos aquí, la insostenibilidad fiscal no tuvo un papel determinante. Ahora bien, una deuda pública en rápido crecimiento, que acabe siendo considerada insostenible por el mercado que la ha venido financiando, puede, obviamente, ser el antecedente y el detonador de un episodio de esas características. Por otro lado, se encuentran déficit 
fiscales y deuda pública significativas en las crisis de Argentina de 1981-82, y nuevamente en la de 2001-02 y se ha argumentado con frecuencia que las mismas se explican por estas circunstancias.

Sin embargo, es claro que el origen de la crisis argentina de 1981-82 no estuvo en las cuentas fiscales. En ese caso sólo la mitad de la deuda externa era pública antes de la crisis y el régimen militar no parecía enfrentar mayores dificultades para ajustar las finanzas públicas. El déficit fiscal y su financiación externa resultaron de decisiones gubernamentales que no plantearon problemas particulares. La política fue ampliamente avalada por los asesores enrolados en el "enfoque monetario del balance pagos", que sostenían entonces que la política monetaria - y solamente la política monetaria - era el instrumento determinante del resultado del balance de pagos y el nivel de reservas. Mientras se mantuviera disciplina y control sobre el crédito interno - se decía - el financiamiento del déficit público no genera problemas. Además, no fue la conducta de los bancos acreedores del sector público la que indujo la crisis, por haber restringido su oferta de financiamiento o elevado su precio. Los bancos internacionales continuaron proveyendo financiamiento al sector público, con baja sobretasa, hasta los últimos momentos de vigencia del régimen cambiario. Tanto en el caso argentino como en el paralelo de Chile, la crisis financiera interna comenzó a manifestarse al menos un año antes del colapso del régimen cambiario.

El caso de la crisis argentina de 2001-02, cuyos aspectos fiscales acabamos de examinar, es diferente. En esta ocasión la deuda pública es la principal componente de la deuda externa del país. El análisis de esta experiencia encuentra también la dinámica macroeconómica de ciclo que se ha descrito arriba, pero ésta se superpone con un déficit fiscal y un continuo crecimiento de la deuda pública, financiada en buena parte con recursos externos. Esto no ocurrió en el primer ciclo de los noventa - el de 1991-95 - sino en el segundo, el que se inicia en 1996, después de la crisis detonada por el efecto tequila.

La emergencia del déficit fiscal se originó, según se describiera en la sección precedente, en el sistema de seguridad social. Por un lado, con la reforma instrumentada a fines de 1994 se trasladó al subsistema previsional privado (las Administradoras de Fondos de Jubilaciones y Pensiones) buena parte de los ingresos del sistema, mientras se mantenía el gasto público en pagos previsionales. Por otro lado, el gobierno dispuso la reducción de las contribuciones patronales, en un intento de mejorar la competitividad debilitada por la apreciación cambiaria. De todas maneras, en la segunda mitad de la década de los noventa, la principal componente incremental del gasto corriente público fueron, tal como hemos visto, los propios intereses de la deuda pública. El aumento de la tasa de interés característico de la fase 
contractiva del ciclo incidió directamente sobre el crecimiento de la deuda pública, contribuyendo a una dinámica perversa de mayor deuda y mayor riesgo [Damill y Frenkel (2003)].

El análisis de sostenibilidad de un inversor detecta en este caso múltiples fuentes de incertidumbre. Por un lado, se verifica la dinámica macroeconómica común a los procesos que desembocan en crisis: el déficit de cuenta corriente y la deuda externa aumentan, hay creciente necesidad de ingresos de capitales y se incrementa la fragilidad financiera externa de la economía como un todo. Por otro lado, en paralelo con ese proceso, se verifican el aumento de la deuda pública y las crecientes necesidades de financiamiento del sector público.

La tendencia al aumento de la prima de riesgo país y de la tasa de interés puede asociarse con la situación de las cuentas externas del país o con la evolución de las finanzas públicas. O con ambas, como de hecho hicieron los informes de los analistas de los fondos de inversión y las agencias calificadoras de riesgo.

Sin embargo, aún cuando las dudas asociadas a la sostenibilidad de la deuda pública hayan pesado significativamente en las evaluaciones de riesgo de los inversores, esto no debería ocultar las fuentes originales del déficit y la deuda del sector público. La principal causa no fue una política fiscal dispendiosa, sino el efecto combinado de la fragilidad externa y el contagio de las crisis de Asia, Rusia y Brasil.

Se concluye que el segundo ciclo del régimen de convertibilidad y la crisis argentina reciente no constituyen un caso excepcional. En su explicación, la navaja de Occam sugiere privilegiar los hechos estilizados que comparte con las otras crisis consideradas.

El FMI y algunos analistas -en forma destacada, el ex Chief Economist del FMI [Mussa (2002)]- son enfáticos en atribuir la crisis al déficit fiscal y a la dinámica de la deuda pública, sin prestar atención a sus orígenes. Hay una sugerencia implícita de que la experiencia hubiera sido sostenible y la crisis no hubiera ocurrido con una política fiscal diferente.

Reconocer que el crecimiento de la deuda pública es un resultado en buena medida endógeno del propio aumento de la prima de riesgo país colocaría al FMI en una posición incómoda y lo obligaría a una autocrítica. En la primera mitad de los años noventa, la institución apoyó intelectualmente y con recursos las políticas de tipo de cambio fijo y apreciado, incluyendo el régimen de convertibilidad adoptado por Argentina en 1991. Más tarde, cuando la crisis de México hizo ostensibles las falencias de esas políticas cambiarias, el FMI cambió su diagnóstico. La nueva orientación reconoció la volatilidad de los flujos de capital y pasó a recomendar políticas de cambio 
flotante. Pero la nueva orientación reservó una calificación favorable para las políticas de tipo de cambio fijo de gran rigidez institucional y legal - como los regímenes de "currency board" o la dolarización. Esta categoría pasó a ser una de las "corner solutions" aceptadas por la nueva ortodoxia [Fischer (2001)]. El paraguas de la nueva ortodoxia alcanzaba para cubrir el régimen de convertibilidad argentino.

El compromiso del FMI con el régimen de convertibilidad tuvo su máxima expresión en el paquete de emergencia acordado a Argentina a fines de 2000. La condicionalidad no incorporaba ningún cambio significativo del esquema de política. El apoyo estaba claramente dirigido a extender la supervivencia del régimen, cuando había claras indicaciones de que era insostenible. Los recursos multilaterales terminaron financiando el pago de los servicios de la deuda y la fuga de capitales. El FMI acordó un desembolso en agosto de 2001, cuando las autoridades argentinas prácticamente en soledad parecían creer que era todavía posible sostener el régimen.

Es comprensible que el FMI prefiera no recordar esa historia. El diagnóstico que atribuye los problemas y la crisis de Argentina exclusivamente a las variables fiscales es conveniente, porque descarga al FMI de toda responsabilidad en los acontecimientos y sus desastrosas consecuencias incluyendo entre éstas no solamente las que cayeron sobre la población, sino también las pérdidas de capital de los inversores externos. Menos comprensible es que posteriormente el FMI haya negado por largo tiempo el mínimo apoyo - la refinanciación de los vencimientos del capital adeudado al organismo - a políticas que intentan administrar las consecuencias de la crisis a que condujeron las políticas que la institución apoyó previamente. Paradójicamente, funcionarios del FMI justificaban esa reticencia con oscuras referencias a "los errores que hemos cometidos con Argentina en el pasado". 


\section{Bibliografía y referencias}

Agosin, M (2000): "Corea y Taiwán en la crisis financiera asiática”, en FrenchDavis, R. (comp.), Crisis Financieras en países "exitosos", CEPAL y McGraw-Hill, Santiago de Chile.

Arellano, J. P. (1983): "De la liberalización a la intervención. El mercado de capitales en Chile, 1974-83", Estudios CIEPLAN, No 11, Santiago de Chile.

Calvo, G.; Leiderman, L. y Reinhart, C. (1996): "Inflows of Capital to Developing Countries in the 1990s", The Journal of Economic Perspectives, Vol.10, Issue 2.

Calvo, G., A. Izquierdo y E. Talvi (2002). Suden stops, the real exchange rate and fiscal sustainability: Argentina's lessons, BID, Washington D.C.

CEPAL (2002): "Growth with stability. Financing for development in the new international context", CEPAL, Santiago de Chile.

Cetrángolo, O. (1994) “El nuevo sistema previsional ¿Una reforma definitiva?”, Serie Notas 2, CECE, Buenos Aires.

Cetrángolo, O, M. Damill, R. Frenkel y J.P.Jiménez (2000). "La sostenibilidad de la política fiscal en América Latina. El caso argentino", en: Talvi, E. y C.Végh (Eds.), ¿Cómo armar el rompecabezas fiscal? Nuevos indicadores de sostenibilidad, BID, Washington, D.C.

Cetrángolo, O, y J.P.Jiménez (2003). "Política fiscal en Argentina durante el régimen de convertibilidad", Serie gestión Pública nº 108, CEPAL, Santiago de Chile.

D’Arista, J. (2002) "Financial Regulation in a Liberalized Global Environment", in Eatwell, J. and Taylor, L. (eds.) International Capital Markets. Systems in Transition, Oxford University Press.

Damill, M. (2000). "El balance de pagos y la deuda externa pública bajo la convertibilidad", Boletín InformativoTechint no 303, Buenos Aires.

Damill, M.; Fanelli, J. M.; Frenkel, R. y Rozenwurcel, G. (1993): "Crecimiento económico en América Latina: Experiencia reciente y perspectivas", Desarrollo Económico No. 130, julio-setiembre, Buenos Aires.

Damill, M y Frenkel, R. (1987): “ De la apertura a la crisis financiera. Un análisis de la experiencia argentina de 1977 a 1982", en BCRA, Ensayos Económicos, № 37, Buenos Aires.

Damill, M. y Frenkel R. (2003) "Argentina: Macroeconomic Performance and Crisis" trabajo preparado para el encuentro Initiative for Policy Dialogue (IPD) Macroeconomic Policy Task Force, Barcelona, España, 2-3 junio, 2003. 
Damill, M., R. Frenkel y R. Maurizio (2002). Argentina, una década de convertibilidad. Un análisis del crecimiento, el empleo y la distribución del ingreso. OIT, Santiago de Chile. (http://www.oitchile.cl).

Damill, M., R. Frenkel y R. Maurizio (2003). "Políticas macroeconómicas y vulnerabilidad social. La Argentina en los años noventa", Serie Financiamiento del Desarrollo, CEPAL, Santiago de Chile.

Díaz Alejandro, C. (1985): "Good-bye Financial Repression, Hello Financial Crash", Journal of Development Economics, vol 19, $\mathrm{N}^{\circ} 1$.

Eatwell, J. (1996): "International Financial Liberalization: The Impact on World Development", ODS Discussion papers series, New York.

Eatwell, J. Y Taylor, L. (2000), Global Finance at Risk: The Case for International Regulation, New York: The New Press.

Edwards, S. (1986): "The Order of Economic Liberalization of the Current and Capital Account of the Balance of Payments" en M. Armeani, Choksi and D. Papargeorgiou (eds.) Economic Liberalization in Developing Countries, London: Basil Blackwell.

Fanelli, J. M. \& Frenkel, R. (1993): "On Gradualism, Shock Treatment and Sequencing", International Monetary and Financial Issues for the 1990s. Research Papers for The Group of Twenty-four, Volume II, United Nations, New York.

Ffrench-Davis, R. (2001): Crisis financieras en países "exitosos", ECLACMcGraw-Hill, Santiago de Chile.

Ffrench-Davis, R. y Arellano, J. P. (1983): "Apertura financiera externa: la experiencia chilena entre 1973-1980", en French-Davis R. (ed.), Las Relaciones Financieras Externas. Su efecto en las Economías Latinoamericanas, Fondo de Cultura Económica, México.

Fischer, S. (2001): "Exchange rates regimes: is the bipolar view correct?", Discurso preparado para la Distinguished Lecture on Economics in Government, auspiciada conjuntamente por la American Economic Association y la Society of Government Economists, en el encuentro de la American Economic Association, New Orleans, January 6, 2001.

FMI (1997): "International Capital Markets. Development, Prospects, and Key Policy Issues", World Economic and Financial Surveys, November 1997, IMF, Washington DC.

Frenkel, R. (1980) "El desarrollo reciente del mercado de capitales en Argentina", Desarrollo Económico, vol.20, № 78, Buenos Aires. 
Frenkel, R. (1983a) "Mercado financiero, Expectativas Cambiarias y Movimientos de Capital", El Trimestre Económico, vol. L (4), Núm.200, México.

Frenkel, R. (1983b): “La apertura financiera externa: el caso argentino”, en French-Davis, R., (ed) Relaciones Financieras Externas y su Impacto en las Economías Latinoamericanas, Fondo de Cultura Económica, México

Frenkel, R. (1995) "Macroeconomic Sustainability and Development Prospects: Latin American Performance in the 1990s", UNCTAD Discussion Papers No. 100, Geneva, August.

Frenkel, R. (2002) "Capital Market Liberalization and Economic Performance in Latin America", in Eatwell, J. and Taylor, L. (eds.) International Capital Markets. Systems in Transition, Oxford University Press.

Frenkel, R. (2003): "From the boom in capital inflows to financial traps", trabajo preparado para el encuentro Initiative for Policy Dialogue (IPD) Capital Market Liberalization Task Force, Barcelona, España, 2-3 junio, 2003.

Gaggero, J. (2003). "La cuestión fiscal bajo la convertibilidad", Buenos Aires, mimeo.

Gaggero, J. y J.C. Gómez Sabaini (2002). Argentina. Cuestiones macrofiscales y políticas tributarias. CIEPP-OSDE, Buenos Aires.

Haussmann, R. y A. Velasco (2002). "Hard money's soft underbelly: Understanding the Argentine crisis", mimeo, Kennedy School of Government, Harvard University.

Krueger, A. (1984): "Problems of Liberalization", en M. Armeani, Choksi and D. Papargeorgiou (eds.) Economic Liberalization in Developing Countries, London: Basil Blackwell, 1986. A. Krueger "Trade Policy in Developing Countries" en R.W.J Jones and P. B. Kenen (eds.) Handbook of International Economics, vol 1, Amsterdam, North Holland.

Melconián, C., R. Santángelo, D. Barceló y C. Mauro (1997). La deuda pública argentina entre 1988 y 1996. Programa de Consolidación y de la Reforma Administrativa y Financiera del Sector Público Nacional, Buenos Aires.

Minsky, H. P. (1975): John Maynard Keynes, Columbia University Press, New York.

Mussa, M (2002): "Argentina and The Fund: From Triumph to Tragedy", Working Papers, Institute for International Economics, Washington D.C. 
Ocampo, J.A. (2003), "Capital-account and counter-cyclical prudential regulations in developing countries", Series Informes y Estudios Especiales N ${ }^{\circ}$ 6, ECLAC, Santiago de Chile.

Robichek, W. (1981): "Some Reflections about External Public Debt Management" en Banco Central de Chile, Alternativas de Políticas Financieras en Economías Pequeñas y Abiertas al Exterior, Estudios Monetarios VII, Santiago de Chile.

Stiglitz, J. (2002), Globalization and its Discontents, W.W. Norton \& Company.

Taylor, L. (1991): Income Distribution, Inflation, and Growth, Cambridge MA: MIT Press.

Taylor, L. (1998), "Lax Public Sector and Destabilizing Private Sector: Origins of Capital Market Crises", en United Nation Conference on Trade and Development, International Monetary and Financial Issues for $\underline{1990 \mathrm{~s}}$, vol. 10, New York.

Teijeiro, M. (1996). La política fiscal durante la convertibilidad. Centro de Estudios Públicos, Buenos Aires.

Williamson, J. (1983). The Open Economy and the World Economy, Basic Books, New York. 


\section{ANEXO}

\section{Sobre la estimación de la deuda pública}

La Ley 24.156, sancionada el 30 de septiembre de 1992, establece y regula la administración financiera y los sistemas de control del sector público nacional. Según el artículo 58, la deuda pública puede ser clasificada en directa e indirecta. En el primer caso, se incluye la deuda que la administración central asume en calidad de deudor principal. En el segundo caso, se incluye la deuda contraída por cualquier persona física o jurídica, ya sea privada o pública, pero que cuenta con su garantía. Se incluye dentro de la deuda pública aquella contraída por el BCRA con organismos multilaterales. Sin embargo, quedan excluidas las obligaciones de los estados provinciales que no cuenten con garantía de la nación. La deuda provincial que cuenta con el aval de la Nación es sólo aquella contraída con organismos multilaterales. De este modo, para estimar la deuda pública consolidada, se adiciona a la deuda pública nacional la deuda provincial que no tiene garantía de la nación.

Se cuenta con cifras oficiales de deuda del sector público nacional a partir de 1993, publicada por la Secretaría de Hacienda, y de deuda provincial a partir de 1996, publicada por la Dirección Nacional de Coordinación Fiscal con las Provincias (DNCP). Es de destacar que las series publicadas por la DNCP incluyen la deuda de las provincias con el Gobierno Nacional. Por tratarse de una deuda intergubernamental no la incluimos en la estimación de la deuda pública consolidada.

Debido a la falta de cifras oficiales, se utilizó, para el período 1991-92, la estimación de deuda pública nacional presentada en Melconián et al. (1997). La deuda provincial para 1991-1995 se estimó a partir del dato de cierre de 1996, adoptando el supuesto de que sus variaciones en cada uno de los años anteriores coincidieron con el déficit fiscal provincial del período correspondiente.

A los efectos de examinar las discrepancias entre los déficit acumulados y las variaciones de deuda (incluidas en el cuadro 5 del texto precedente), se consideraron las cifras de diferencias de cambio y de reconocimiento de deudas de períodos anteriores que se presentan desagregados en las estadísticas oficiales de deuda desde 1995. Las diferencias de cambio para los años 1992-1994 se obtuvieron de "La posición de inversión internacional de Argentina" publicada por la Dirección Nacional de Cuentas Internacionales (DNCI) en 1998. Para estimar el reconocimiento de deuda de períodos anteriores en el período 1992-1994 se utilizó la información publicada en Teijeiro (1996). 
El rescate de deuda por privatizaciones se obtuvo de "El Proceso de Privatizaciones en la Argentina desde una perspectiva del Balance de Pagos", publicado por la DNCI en 1999. Por otra parte, la estimación de la quita de la deuda con el Plan Brady es la presentada en Melconián et al. (1997).

Los datos de la deuda del BCRA con organismos multilaterales se obtuvieron del Balance Consolidado del Sistema Financiero publicado por esa entidad.

\section{Sobre la estimación del déficit consolidado del Sector Público no Financiero, base devengado}

El resultado del Sector Público Nacional no Financiero incluye el resultado del Sector Público no Financiero más el resultado cuasifiscal del BCRA. El Sector Público no Financiero está conformado por la Administración Nacional (Administración Central, Instituciones de Seguridad Social y Organismos Descentralizados) y las Empresas Públicas y otros (por ejemplo, universidades). El resultado Sector Público Consolidado está formado por el resultado del Sector Público Nacional no Financiero y el resultado de las Provincias.

Debido a la falta de datos oficiales completos para este nivel jurisdiccional, las estimaciones del resultado del Sector Público Nacional no Financiero para los años 1991, 1992 y 1993 provienen de Cetrángolo et. al. (2000).

Los datos del resultado del Sector Público Nacional no Financiero para los años comprendidos entre 1994 y 2001 provienen de las Cuentas AhorroInversión-Financiamiento del Sector Público Nacional y de los Boletines Fiscales publicados por la Secretaría de Hacienda.

Es de destacar que con el objeto de obtener una serie homogénea se procedió a la corrección de algunos rubros. En particular, las cifras de ingresos no incluyen los obtenidos por las empresas públicas. El resultado obtenido por las mismas se adiciona en el ítem correspondiente a Gastos Primarios. Para el período 1991-1993 se considera el déficit corriente de las empresas públicas; mientras que los años posteriores se considera el déficit financiero de las empresas públicas. El año 2001 considera el resultado base caja de las empresas públicas "antes de contribuciones figurativas". De todos modos, en los años noventa el resultado de las empresas públicas se tornó de muy escasa significación cuantitativa.

Tanto los Ingresos como los Gastos Primarios fueron considerados antes de Contribuciones Figurativas. Los datos de Gasto Primario Provincial y Déficit Provincial para el período 1991-2001 se obtuvieron de la "Información fiscal y financiera" publicados por la Dirección Nacional de Coordinación Fiscal con las Provincias. 


\section{Resultados fiscales de la década de los noventa}

base devengado, en millones de pesos, a precios corrientes

\begin{tabular}{|r|r|r|r|r|r|r|r|}
\hline Año & $\begin{array}{c}\text { Resultado } \\
\text { Primario sin } \\
\text { Seguridad Social } \\
(1)\end{array}$ & $\begin{array}{c}\text { Resultado de } \\
\text { la Seguridad } \\
\text { Social } \\
(2)\end{array}$ & $\begin{array}{c}\text { Resultado } \\
\text { Primario }\end{array}$ & $\begin{array}{c}\text { Pagos de } \\
\text { Intereses }\end{array}$ & $\begin{array}{c}\text { Resultado del } \\
\text { Sector Público } \\
\text { Nacional } \\
(5)\end{array}$ & $\begin{array}{c}\text { Resultado de } \\
\text { las Provincias }\end{array}$ & $\begin{array}{c}\text { Resultado del } \\
\text { Sector Público } \\
\text { Consolidado } \\
(7)\end{array}$ \\
\hline 1991 & 2.631 & -1.409 & 1222 & 1501 & -279 & -1501 & -1780 \\
\hline 1992 & 6.808 & -2.005 & 4802 & 3320 & 1483 & -596 & 887 \\
\hline 1993 & 5.007 & -467 & 4540 & 2570 & 1970 & -1757 & 213 \\
\hline 1994 & 3.581 & -2.546 & 1035 & 3192 & -2157 & -2190 & -4347 \\
\hline 1995 & 3.018 & -3.402 & -383 & 4224 & -4608 & -3248 & -7856 \\
\hline 1996 & 3.168 & -6.394 & -3225 & 4158 & -7383 & -1192 & -8575 \\
\hline 1997 & 7.780 & -6.398 & 1382 & 5653 & -4271 & -113 & -4384 \\
\hline 1998 & 8.194 & -6.778 & 1416 & 6630 & -5214 & -1950 & -7164 \\
\hline 1999 & 7.391 & -7.700 & -309 & 8176 & -8485 & -4124 & -12609 \\
\hline 2000 & 11.671 & -8.061 & 3611 & 9645 & -6034 & -3313 & -9347 \\
\hline 2001 & 7.594 & -7.117 & 477 & 10820 & -10343 & -6372 & -16715 \\
\hline
\end{tabular}

$$
\begin{aligned}
& (3)=(1)+(2) \\
& (5)=(3)-(4) \\
& (7)=(5)+(6)
\end{aligned}
$$

Fuente: elaboración propia a partir de datos del Ministerio de Economía, y de Cetrángolo et al. (2000) (para 1991-94). 


\section{Deuda del Sector Público Nacional, Provincial y Consolidada}

en millones de pesos, a precios corrientes

\begin{tabular}{|c|r|r|r|r|}
\hline Año & $\begin{array}{c}\text { Deuda del Sector } \\
\text { Público Nacional menos } \\
\text { deuda de las provincias } \\
\text { con Organismos } \\
\text { Multilaterales } \\
(1)\end{array}$ & $\begin{array}{c}\text { Deuda Provincial } \\
\text { corregida }\end{array}$ & Deuda Consolidada & $\begin{array}{c}\text { Deuda del BCRA con } \\
\text { organismos } \\
\text { multilaterales }\end{array}$ \\
\hline 1991 & 52454 & $(2)$ & $(3)$ & 55472 \\
\hline 1992 & 56715 & 3018 & 60329 & 3494 \\
\hline 1993 & 63111 & 3614 & 68482 & 3472 \\
\hline 1994 & 73005 & 5371 & 80566 & 4702 \\
\hline 1995 & 77794 & 7561 & 88603 & 7375 \\
\hline 1996 & 87689 & 10809 & 99690 & 7497 \\
\hline 1997 & 91812 & 12001 & 103225 & 6994 \\
\hline 1998 & 102691 & 11413 & 115622 & 6595 \\
\hline 1999 & 112370 & 12931 & 128699 & 5770 \\
\hline 2000 & 119079 & 16329 & 140180 & 6265 \\
\hline 2001 & 126119 & 21101 & 156042 & 15132 \\
\hline
\end{tabular}

(1) No incluye la deuda del Banco Central.

(3) $=(1)+(2)$

Fuente: elaboración propia a partir de datos del Ministerio de Economía, y de Melconian et.al. (para 1991-1992), y Balance Consolidado del Sistema Financiero publicado por el BCRA.

Nota: los stocks de deuda corresponden a saldos a fin de período. 
Déficit fiscal y variación de la deuda pública

en millones de pesos, a precios corrientes

\begin{tabular}{|c|c|c|c|c|c|c|c|c|c|}
\hline Año & $\begin{array}{c}\text { Déficit del } \\
\text { Sector } \\
\text { Público } \\
\text { Consolidado } \\
\text { (1) } \\
\end{array}$ & \begin{tabular}{|c|} 
Variacion \\
de la Deuda \\
Pública \\
Bruta \\
$(2)$ \\
\end{tabular} & $\begin{array}{c}\text { Discrepancia } \\
\text { (3) }\end{array}$ & $\begin{array}{c}\text { Intereses } \\
\text { capitalizados } \\
(4)\end{array}$ & \begin{tabular}{|c|} 
Deudas \\
de otros \\
períodos \\
$\quad(5)$
\end{tabular} & $\begin{array}{c}\text { Diferencias } \\
\text { de cambio } \\
(6)\end{array}$ & $\begin{array}{l}\text { Variación de } \\
\text { activos } \\
\text { (7) }\end{array}$ & $\begin{array}{c}\text { Rescate de títulos } \\
\text { de deuda por } \\
\text { privatizaciones } \\
\text { (8) }\end{array}$ & $\begin{array}{c}\text { Otros } \\
\text { factores } \\
(9)\end{array}$ \\
\hline 1992 & -887 & 4857 & 5744 & 2006 & 7196 & -1433 & 2366 & 131 & -4260 \\
\hline 1993 & -213 & 8154 & 8367 & -1104 & 10039 & -246 & 2882 & 4744 & 6186 \\
\hline 1994 & 4347 & 12084 & 7737 & 1353 & 5624 & 1080 & -2043 & 2236 & 3959 \\
\hline 1995 & 7856 & 8037 & 181 & 1198 & 1716 & 1103 & -45 & 40 & -3750 \\
\hline 1996 & 8575 & 11087 & 2511 & 1170 & 1231 & -1661 & 2112 & 0 & -340 \\
\hline 1997 & 4384 & 3535 & -848 & 767 & 945 & -2823 & 776 & 0 & -513 \\
\hline 1998 & 7164 & 12397 & 5233 & 531 & 1011 & 1826 & 304 & 0 & 1561 \\
\hline 1999 & 12609 & 13077 & 469 & 408 & 1970 & -2483 & \begin{tabular}{|c|}
-479 \\
\end{tabular} & 0 & 1053 \\
\hline 2000 & 9347 & 11481 & 2133 & 367 & 1514 & -2467 & 454 & 0 & 2265 \\
\hline 2001 & 16715 & 15862 & -853 & 318 & 1452 & -2541 & -432 & 0 & 350 \\
\hline
\end{tabular}

(2) No incluye la deuda del Banco Central.

(3) $=(2)-(1)$

(3) $=(4)+(5)+(6)+(7)+(8)+(9)$

(8) Incluye, en 1993, 2323 millones de dólares correspondientes a la estimación de la quita generada por el Plan Brady.

Fuente: elaboración propia a partir de datos del Ministerio de Economía, Melconian et.al. (1997) y Cetrángolo et.al. (2000) y Teijeiro (1996). 